\title{
Preface: 5th San Luis Pan-American Conference on Surfaces, Interfaces and Catalysis
}

\author{
Donna A. Chen · Jose A. Rodriguez • \\ Francisco Zaera
}

Published online: 26 January 2011

(c) The Author(s) 2011. This article is published with open access at Springerlink.com

The following Special Issue of Topics in Catalysis contains contributions from the participants of the Fifth San Luis Conference on Surfaces, Interfaces and Catalysis, a PanAmerican Advanced Studies Institute that took place in Sao Pedro, Brazil from April 9th to April 19th, 2010. This was the fifth in a series of symposia targeted to unite Latin American and US and European scientists in the areas of surface science and catalysis. The symposium was organized by Professor Francisco Zaera of the University of California, Riverside and Professor Pedro Nascente of the Federal University of São Carlos, Brazil.

The original San Luis conference was organized in August of 1994 to celebrate the 400th anniversary of the founding of the city of San Luis, Argentina. That conference, which was financed primarily by the State of San Luis with supporting funds from the Argentinean National Government, was aimed at bringing together theoreticians and experimentalists working in the area of surface chemistry, primarily in connection with catalysis, to facilitate international communication, and to expose students working in Argentina to leading international scientists. The conference was a great success, more than fulfilling the expectations of the organizers. It featured attendees from many nations, including the United States, the United

D. A. Chen

Department of Chemistry and Biochemistry, University of South Carolina, Columbia, USA

J. A. Rodriguez

Chemistry Department, Brookhaven National Laboratory,

New York, USA

F. Zaera $(\bowtie)$

Department of Chemistry, University of California,

Riverside, USA

e-mail: zaera@ucr.edu
Kingdom and Mexico as well as from Argentina, itself. The quality of the work presented there is reflected in the publication of the conference papers in the leading international journal Langmuir. Several new collaborative research projects were also started between Argentinean universities and foreign institutions.

Encouraged by that success, a Second San Luis Symposium was organized in Mar del Plata, Argentina, in April of 2000. No local moneys were available that time, and funding came primarily from the US National Science Foundation. Again, the results were significantly better than expected. There was a substantial increase in international participation, with people attending from the United States, Mexico, Venezuela, Brazil, Argentina, the United Kingdom, France, Italy and Japan. New collaborations were established, and the proceedings were published in The Journal of Molecular Catalysis A: Chemical. A few changes were implemented, including a following Summer School on Surface Science. Fellowships were given to a few US graduate students with the intent to foster collaborations with people early in their professional careers.

The Third San Luis Summer School and Symposium on Surfaces, Interfaces and Catalysis was held in Merida, Venezuela in 2004 with 70 attendees and about 40 students from fourteen countries in Europe and north and south America, 40 oral presentations, and almost 50 poster presentations, the proceedings of the conference were again published in The Journal of Molecular Catalysis A: Chemical. Finally, the Fourth San Luis Summer School and Symposium on Surfaces, Interfaces and Catalysis was held in Cuernavaca, Mexico in 2007 with 120 attendees from fifteen countries (United States, Canada, Japan, Israel, United Kingdom, Denmark, Spain, Germany, France, Mexico, Columbia, Argentina, Chile, Brazil and Venezuela). There were a total of 39 oral presentations and 93 posters, 
presented in three separate sessions. The proceedings were once more published in a special issue of The Journal of Molecular Catalysis: Chemical.

The increasing success of these meetings has attested to the level of maturity they have achieved. To continue with the tradition and to build on our past success, the Organizing Committee is aiming to continue the San Luis Symposium as a periodic event with locations that will rotate among the different Latin American Countries. With that in mind, the Fifth San Luis Summer School and Symposium on Surfaces, Interfaces and Catalysis, was held in São Pedro, Brazil. This conference was financed primarily by the U.S. National Science Foundation under their PASI program, but additional funding was secured from the Universidade Federale de São Carlos, and from two companies, Kratos Analytical and Specs. Official endorsement was also secured from the American Vacuum Society, which helped with advertising and logistics.

The following Committees were assembled:

General Organizing Committee:

- Francisco Zaera (University of California, Riverside, USA)

- Wilfred Tysoe (University of Wisconsin, Milwaukee, USA)

- Giorgio Zgrablich (Universidad Nacional de San Luis, Argentina)

International Advisory Committee:

United States

- Professor Donna A. Chen (University of South Carolina, Columbia)

- Professor Andrew Gellman (Carnegie-Mellon University, USA)

- Professor Carol Hirschmugl (University of Wisconsin, Milwaukee)

- Dr. Cynthia J. Jenks (Ames Laboratory, Iowa State University, Ames)

- Dr. José Rodriguez (Brookhaven National Laboratory, USA)

- Professor Wilfred T. Tysoe (University of Wisconsin, Milwaukee, USA)

- Professor Francisco Zaera (University of California, Riverside, USA)

Europe

- Professor Hans-Joachim Freund (Fritz-Haber-Institut, Germany)

- Professor Brian E. Hayden (University of Southampton, U. K.)

- Professor Rasmita Raval (University of Liverpool, U. K.)

\section{Latin America}

- Professor Celso Aldao (Universidad Nacional de Mar del Plata, Argentina)

- Professor Victor Fuenzalida (Universidad de Chile)

- Professor Mireya R. Goldwasser (Universidad Central de Venezuela)

- Professor George G. Kleiman (State University of Campinas, Brazil)

- Professor Elsa C. Menchaca-Campos (Universidad Autónoma de Morelos, México)

- Professor Juan Carlos Moreno Piraján (Universidad de Los Andes, Bogotá)

- Professor Giorgio Zgrablich (Universidad Nacional de San Luis, Argentina)

Brazilian Local Organizing Committee:

- Professor Andrea B. Latge (Fluminense Federal University)

- Professor Pedro A. P. Nascente (Federal University of Sao Carlos)

- Professor Andre A. Pasa (Federal University of Santa Catarina)

- Professor Maria Luiza Rocco (Federal University of Rio de Janeiro)

The San Luis V event consisted of a conference and a Summer School. The Summer School portion was split into two parts, to cover two weekends: the first, on April 10th and 11 th, with lectures primarily being given by the invited speakers from Europe and the United States covering primarily issues of surface science, and the second on April 17 th and 18th primarily presented by speakers from Latin America and with emphasis on catalysis. This arrangement allowed the speakers during the first Summer School session to provide a background for their talks, which were presented during the subsequent week. The latter session was more informal, allowing students to ask questions about the talks during the previous week and to obtain clarification of what they had heard. The conference itself was held during the week, between April 12th and 16th, and consisted of a series of invited talks and two poster sessions. Two new educational elements were introduced: (1) a lecture on the ethics of research and on ways to plan research projects and prepare good publications; and (2) an oral session for the presentation of the posters by the winners of the PASI Fellowships. These two additions were deemed great successes. The second in particular offered an opportunity for the students to improve on their presentation skills. Some of the Latin American participants had not had the chance to do this before, and much appreciated the feedback they received by our friendly audience. 
The Pan-American Advanced Studies Institute was quite successful, with 55 attendees from 10 countries (United States, United Kingdom, Spain, Germany, Mexico, Colombia, Argentina, Chile, Brazil and Venezuela). The feedback that we received from the participants was extremely enthusiastic, and several people commented that this was one of the best conferences that they had attended both from a scientific point of view and the social interactions. The PASI funds covered the traveling expenses of 20 international senior scientists, including 8 from the US, 6 from Brazil, and 6 from other countries within Latin America (the 6 Europeans paid their own airfare). In addition, 11 PASI Fellowships were awarded in three categories, 5 to US students, 5 to Latin American students and junior faculty, and 1 to a Brazilian student. An additional 7 senior scientists, mostly from Latin America, 5 Brazilians, and 6 students registered for the event. The final group was quite diverse, both in terms of geographical origin and regarding gender and race. The percentage of female participants averaged approximately $45 \%$ of the total attendance, and this proportion was seen across all sectors: junior versus senior scientists and as a function of continent of origin. In addition, from the US participants, more than $30 \%$ were of Hispanic origin.

There were a total of 24 one-hour lectures in the PASI School, 29 one-hour invited oral presentations, 11 10-min presentations by the PASI Fellowship winners, and 29 posters presented in two separate sessions.

Here we have assembled 34 written contributions from participants to the San Luis V event, many from the invited speakers. The contributions focus on fundamental aspects of surface science, theoretical modeling of gas-solid interactions, and catalytic and photocatalytic processes. We believe that the quality of the conference is nicely reflected in the high caliber of the science reported in this issue. We hope that you find this reading rewarding. We also look forward to the next San Luis conference.

Open Access This article is distributed under the terms of the Creative Commons Attribution Noncommercial License which permits any noncommercial use, distribution, and reproduction in any medium, provided the original author(s) and source are credited. 